\title{
Exploring the Role of Employees in the Delivery of the Brand: A Case Study Approach
}

\author{
Ceridwyn King \\ Associate Lecturer \\ Department of Tourism, Leisure, Hotel and Sport Management \\ Griffith Business School \\ Griffith University \\ Gold Coast \\ Debra Grace (PhD) \\ Lecturer \\ Department of Marketing \\ Griffith Business School \\ Griffith University \\ Gold Coast
}

\begin{abstract}
Employees are now viewed as playing a crucial role in brand management as they facilitate the interface between the organization and the market (Harris and Ogbonna, 2000). This study, therefore, examines the role of employees in the delivery of the brand and, in doing so, furthers our understanding of an area that, to date, has received little empirical attention from an operational management perspective. This study adopted a case study approach and data were gathered via semi-structured interviews with mangers of a customer-focused organization. Several themes were identified from the interviews, namely, control, foundation, internal marketing, management role, direction, employee satisfaction, enhancers and element of control. As such, these themes provide the foundation for the discussion and implications of this study.
\end{abstract}

\section{Key Words}

Branding, Employees, Case Study, Qualitative

\section{SUBMITTED TO:}

\section{Qualitative Market Research: An International Journal}




\section{INTRODUCTION}

Organizations are continually striving to create a sustainable advantage in an increasingly competitive market (Sureshchandar, Rajendran and Anantharaman, 2002). Creating such a competitive advantage has given rise to schools of thought such as brand management (e.g. Aaker and Joachimsthaler, 2000; de Chernatony and Dall'Olmo Riley, 1998), which emphasise the customer as the central element of organisational decision-making. As such, brand management has become an area of interest in the marketing discipline over the last couple of decades (Noble, Rajiv and Kumar, 2002) in recognition that brands reflect consumers' perceptions of an organization (Keller, 1998) as well as represent strong financial indicators of organizations (Kerin and Sethuraman, 1998).

Organizations that have developed successful brands have created a culture in which, according to Noble et al (2002), all areas of the organization are committed to the branding process. This being the case, employees are now viewed as playing a crucial role in brand management as they facilitate the interface between the organization and the market (Harris and Ogbonna, 2000), thus making a significant contribution to the organization's competitive advantage. Therefore, ensuring that senior management's desired positioning in the market is consistent with what is actually being delivered, is vitally important if the brand is to succeed. This study, therefore, examines the role of employees in the delivery of the brand from an operational management perspective, and, in doing so, furthers our understanding of an area that, to date, has received little attention. 


\section{LITERATURE REVIEW}

The evolution of brand management overtime can be mapped against the changing nature of organisational focus from product orientation to market/customer orientation. Early literature regarding brands focussed on the definition presented in 1960 by the American Marketing Association - a brand is a name, term, sign, symbol or design or a combination of them intended to identify the goods or services of one seller and to differentiate them from those of competition. As commercial environments have become more competitive, today's brands represent so much more than visual realities (McDonald, de Chernatony and Dall'Olmo Riley, 2001). According to Alvin Achenbaum (Keller, 1998) the brand represents the sum total of consumer's perceptions and feelings about the product's attributes and how they perform. Consumers' perceptions also consider the brand name and what it stands for as well as the company associated with the brand in order to distinguish the brand from its competitors (Simoes and Dibb, 2001). In recognition of the introduction of the consumer's role in the definition of a brand, de Chernatony and Dall'Olmo Riley (1997) argue that consumers ultimately decide the fate of brands today. Successful brands have the power to command a premium price among customers and a premium stock price among investors (Khermouch, Holmes and Ihlwan, 2001).

It is, therefore, evident that brands derive many benefits for both the organisation and the consumer (Keller, 1998; Grace and O'Cass, 2002). The link between financial benefits attributed to the organisation and consumer benefits is apparent. This is so because financial benefits are realised by organisations through the consumer holding strong, favourable associations of the brand (Keller, 1993; Lassar, Mittal and Sharma, 1995; Keller, 1998). The link between consumers' perceptions and positive financial outcomes for the organisation has given rise to an increased emphasis on brand 
management or brand nurturing (Thakor and Katsanis, 1997; Schultz, 1999), and is dependant on an organisation being customer focussed (de Chernatony and Dall'Olmo Riley, 1997).

The significance of the link between the organisation and the consumer in the brand management function is evident in a view widely held by brand practitioners and articulated in the research of de Chernatony and Dall'Olmo Riley (1998) who proposed the DOUBLE VORTEX Model shown in Figure 1. The Double Vortex Model (de Chernatony and Dall'Olmo Riley, 1998) reflects the transition of how brands have changed since the original definition of brands by the AMA in 1960. Based on de Chernatony and Dall'Olmo Riley's (1998) research it might be suggested that brand management needs to consider incorporating the input of the organisation as well as the output as represented by consumer perceptions. The branding process starts with managers devising brand plans, yet ends with consumers choosing brands based on perceptions about the fit between their functional and emotional needs and the brands' functional and symbolic benefits (de Chernatony and Dall'Olmo Riley, 1997). A dominant theme among brand experts, which emerged in de Chernatony and Dall'Olmo Riley's (1997) research, subsequent to the research pertaining to the Double Vortex Model, suggests that consistency between brand plans and consumers perceptions is related to organisational success.

\section{---Take in Figure 1 ----}

With the increasing emphasis on ensuring consistency between the projected brand image and consumer's own perceptions of the brand (Bachman, 2001), the role of employees, as representing a source of customer information (Harris and de 
Chernatony, 2001), needs to be considered. Employees constitute the interface between a brand's internal and external environment and can have a powerful impact on how consumers perceive the brand and the organisation (Schneider and Bowen, 1985; Balmer and Wilkinson, 1991, Harris and de Chernatony, 2001; McDonald et al, 2001). It is, therefore, essential that employees' behaviour is consistent and, thus, reinforces a brand's advertised benefits. If inconsistent, the credibility of the brand will be undermined (Samli and Frohlich, 1992).

As well as providing an interrelated and comprehensive network of consumer perceptions, the brand also plays an important role in providing a central focus for all employees (McDonald et al 2001). As organizations seek to project a consistent image of their brand to consumers, it is necessary for all employees involved in the provision of the product or service, (not just the employees with the customer interface) to be aware of their marketing responsibilities (de Chernatony and Dall'Olmo Riley, 1997; Simoes and Dibb, 2001). This marketing responsibility of all employees gives rise to the term Part Time Marketers as coined by Gummesson (1991).

Employees, however, are human beings, not robots; therefore inconsistencies in the performance of tasks are inevitable causing variation in the outcomes delivered (Rafiq and Ahmed, 2000). As consistency is a crucial element of effective brand management, employees need to comprehend the appropriate behaviour or actions to exhibit when interacting with consumers and these should be based on the brand's core values. Organisations, according to Harris and de Chernatony (2001), need to clearly communicate the brand's purpose to employees to inspire and assist them to understand their role in relation to the brand. In other words, the brand message needs to be conveyed internally so that employee behaviour is guided. 
For employees to be customer conscious, they need to exhibit behaviours and actions that support the organisation's brand. The development and sustainability of enthusiasm for employees to be customer oriented requires continuous management support (George, 1990; Varey, 1995), which is enabled through the adoption of a systematic internal marketing philosophy. According to George (1990), an internal marketing philosophy operates as a holistic management process that integrates multiple levels of an organisation. Internal marketing ensures that all employees, at all levels, understand and experience the business and its various activities and campaigns in the context of an environment that supports customer consciousness. Internal marketing (IM) also prepares and motivates employees to act in a service-oriented manner (George, 1990; Rafiq and Ahmed, 2000). It is through the employees' comprehension of the logic and benefit of being customer oriented that Rafiq and Ahmed (2000) propose that IM can lead to greater customer satisfaction.

The increased emphasis on IM in the literature and its contribution to service quality and satisfaction is based on the notion that organisations that consistently deliver high quality service to customers are most likely to achieve economic success (Asif and Sargeant, 2000; Sureshchandar, Rajendran and Anantharaman, 2002). A contributing factor to economic success is customer retention and loyalty, which is engendered through customer satisfaction (Sureshchandar et al, 2002). As such, customer satisfaction has become a marketing imperative, with many organisations realizing the value of satisfied customers in terms of positive brand attitudes, positive word of mouth and brand loyalty (Spreng, Harrell and MacKoy, 1995). Therefore, satisfaction has become a core concept that is at the crux of marketing theory and practice (Spreng and MacKoy, 1996). Coupled with satisfaction in the literature is service quality, as academics seek to establish the 
link between the two highly correlated, yet distinct constructs (Sureshchandar et al 2002).

The marketing literature suggests that the ability to improve perceived service quality is premised by the organisations ability to minimize the effects of the inherent characteristics of services, namely intangibility, inseparability, perishability and heterogeneity (Keller, 1998; de Chernatony and Dall'Olmo Riley, 1999). Minimizing the effects of service characteristics according to Levitt (1972), would suggest the use of careful planning, control and automation (where possible). In addition, regular reviews of performance improvement and consumer reaction is necessary to improve the service quality outcome. This "industrialized" view (de Chernatony and Dall'Olmo Riley, 1999) of managing a quality outcome suggests that systems and procedures are the premise upon which employees should define their roles and responsibilities in order to deliver service quality. It implies a rigid structure and an almost inflexible approach unlikely to accommodate differing consumer needs (de Chernatony and Dall'Olmo Riley, 1999).

The "industrialized" view fails to consider the realities of the human element in the provision of a service and its ability to customize each brand experience so as to better satisfy the particular needs of each customer (de Chernatony and Dall'Olmo Riley, 1999). While it is appropriate to implement systems and procedures to minimize the human error inherent in any service transaction, the standards prescribed need to be adaptable (de Chernatony and Dall'Olmo Riley, 1999) in order for all consumer needs to be fulfilled. Adaptable standards allow employees to retain the flexibility to deal with different people in different situations, while still conforming to the brand concept (de Chernatony and Dall'Olmo Riley, 1999). Without the ability to change the service delivery process to better serve the requirements of the customer, within the context of 
the brand promise, the optimal customer satisfaction rating is unlikely to be achieved. In support of this, de Chernatony and Dall'Olmo Riley (1999) argue that making brand management an "internal" as well as "external" activity may help ensure consistency across time and differing situations, without having to impose inflexible codes of practice.

As organisations strive to deliver superior service quality that engenders customer satisfaction in order to achieve a competitive advantage, the role of brand management, becomes a focus for the entire organisation. In an increasingly competitive environment, the ability of the employee to positively (or negatively) impact an organisation's success, gives rise to employees being considered to be central (Harris and de Chernatony, 2001) to the brand building process. It, therefore, becomes crucial to consider the implications of brand management inside the organisation (Harris and de Chernatony, 2001) and the alignment of the internal (employee) actions with the external (consumer) perceptions. As such, based on the review of the literature, several research questions are posed in order to further understand the methods by which an organisation can ensure the delivery of service quality is aligned with the brand.

\section{RESEARCH QUESTIONS}

In order to understand the implications of the adoption of brand management strategies, it is necessary to explore the findings of the literature within an identified brand focussed organisation. In particular, as management support is considered to be the single most important component in guiding employee behaviour (George, 1990; Harris and de Chernatony, 2001; Pulendran et al 2000), investigation as to managers' perspectives of what is required for employees to deliver service quality in alignment with the brand, is warranted. 
Employees' ability to deliver on the communicated brand promise consistently is suggested to be dependant on the employee's awareness of the brand (McDonald et al, 2001; Harris and de Chernatony, 2001; Schneider and Bowen, 1985; Balmer and Wilkinson, 1991). The ability of the employee to deliver the communicated brand promise consistently and, thereby, match consumers' perceptions is based on the premise that such efforts will promote high service quality and thereby deliver superior organisational performance as measured by customer satisfaction (Kotler, Armstrong, Meggs, Bradbury and Grech, 1999). Achievement of the desired level of service quality, as evaluated individually by consumers, is suggested to require a semi-customised approach (de Chernatony and Dall'Olmo riley, 1999) to service quality management i.e. systems and procedures with flexibility to change. Thus, it is on this basis that the following research questions are posed.

RQ1: To what extent do managers believe that the delivery of service quality in alignment with the brand is dependant upon the implementation of systems and procedures?

RQ2: Apart from the implementation of systems and procedures, what other factors do managers believe assist employees in delivering service quality in alignment with the brand promise?

RQ3: To what extent do managers believe that consumer knowledge/awareness is necessary to supplement the systems and procedures implemented to deliver service quality in line with the brand promise? 
RQ4: To what extent do managers believe that employee empowerment is necessary to supplement the systems and procedures implemented to deliver service quality in line with the brand promise?

The articulation of these four research questions provides the necessary guidance to further understand the ingredients to ensure employees deliver the appropriate service quality in alignment with the brand. With the direction afforded by the identification of the research questions, further contribution to the existing body of knowledge is enhanced.

\section{RESEARCH DESIGN}

The research methodology chosen to address the research questions of this study was qualitative in nature. As such, a single case study technique was utilized and data was collected via semi -structured interviews. Selection of the case, a description of the interview participants and the interview protocol are further discussed.

\section{Methodology}

Qualitative approaches are used to inductively and holistically understand human experience in context-specific situations (Amaratunga, Baldry, Sarshar, and Newton, 2002; de Ruyter and Scholl, 1998). Qualitative research has been characterised by the use of small samples and offers insight into questions that address the way people think about a certain subject and why they think that way as opposed to how many people share a certain opinion (de Ruyter and Scholl, 1998). In other words, qualitative research tries to understand a particular phenomenon rather than uncover causal relationships. 
As the scope of this study is concerned with exploring the role of employees in the delivery of the brand, the method employed in this study is similar to that utilized in the brand management literature, namely qualitative (e.g. de Chernatony and Dall'Olmo Riley, 1997; de Chernatony and Dall'Olmo Riley, 1998). More specifically, as this research was aimed at eliciting managers' views in relation to the influence of the brand in terms of the effective performance of employee's roles, the adoption of a qualitative approach was deemed to be the most relevant methodology.

\section{Case}

The selection of managers for this study needed to be drawn from an organization that actively promoted itself as being market oriented, employing brand management techniques to ensure superior organizational performance. In other words, the research needed to be site specific i.e. a single case design, as it had to focus on a setting where brand management strategies take place (Marshall and Rossman, 1997). Further to this, as the research questions posed referred to managers' perspectives, Marshall and Rossman (1997) argue that as human actions, in this case perceptions, are influenced significantly by their setting in which they occur, the study of interest should be conducted in the managers' natural setting. As such, it was important that the participants in this study were selected from the same organization or case so as to ensure consistency among the organizational setting.

A case study methodology was deemed to be the most effective methodology based on the argument of Yin (1994) who advocates the use of case studies where the researcher wants to cover contextual conditions, for example the organisation's brand. Contextual conditions, was the motivation for Hill and McGowan (1999) using a single case study methodology in their research. In relation to this study, the organisation's brand is seen 
as playing an important role in providing focus for the employees of that organisation (McDonald et al, 2002). Such contextual conditions, influence attitudes and behaviours of employees (Harris and de Chernatony, 2001). Further to this, a brand in its very nature is different from one organisation to another (Kennedy, Lassk and Goolsby, 2002). As such, the case study methodology allows the phenomenon, to be described 'in-depth' and 'in the round' (Birley and Moreland, 1998) and in doing so, providing the detail that would otherwise be overlooked if another methodology were chosen e.g. survey.

While there are criticisms or limitations associated with the selection of a single case study methodology, namely, putting "all your eggs in one basket" and fears about the uniqueness of conditions surrounding the case (e.g. special access to a key informant) (Yin, 2003), for the purpose of this study, a single embedded case design was selected for two reasons. Firstly, as manager's perspectives are influenced by organisational culture, a single case allows for the same organisational influences to be accounted for and, therefore, satisfies the criteria for a unique or extreme case. Secondly, as operational managers' perspectives of the impact of brand management on the employee role has not previously been explored, the criteria for revelatory is satisfied. To aid in the comprehension of a single case design, subunits within the case were selected, satisfying the criteria for an embedded case, as was demonstrated in the Joia (2002) in their application of a single case study research methodology.

The organisation selected for this study was located in Australia, with over 2000 employees and operations that ran 7 days a week, 24 hours a day. The organisation 
was deemed to be relevant as it actively promoted itself to be market oriented, adopting brand management practices as indicated in their 2003 business plan.

\section{Participants}

Having identified the organisation, it was necessary to specify the population from which the subunits of the case were selected (Zikmund, 1997). The purpose of this study was to explore the perspective of managers who guide or influence employee behaviour. In reviewing the organizational structure of the organization, it was the middle management and supervisory level that has maximum interaction with employees, thus directing their behaviour. As such, a sample of middle management and supervisors representative of the six sub-cultures or divisions within the operation, were selected for interviews. These divisions represented were Finance; Hotel; Gaming; Human Resources; Food and Beverage; and Other (Purchasing, IT, Marketing, Surveillance, Public Relations).

Ten interviews were conducted which included six males and four females, ranging in age from 27 years to 55 years. The average years of service was 7.6 years with the minimum being 1 year and the maximum years of service being 18 years. For a profile of the participants refer to Table 1 . In departments where there are several hundred employees, namely, Hotel, Gaming and Food and Beverage, two managers were selected. Further to that, as the division labeled as "Other" contains several smaller departments; two managers from different departments in the "Other" division were selected. 


\section{Interview Protocol}

The selection of semi structured interviews was deemed to be the most effective method of data collection to address the research questions due to the ability to get large amounts of data quickly, the ability to follow up and seek clarification and the need to rely only on a single primary method for gathering data (Marshall and Rossman, 1999). In addition, researchers in this area of study have extensively used interviews (e.g. de Chernatony and Dall'Olmo Riley, 1997; de Chernatony and Dall'Olmo Riley, 1998; Asif and Sargeant, 2000; Grace and O'Cass, 2002). As the objective of this study is to uncover and describe the participants' perspectives, employment of semi structured interviews as the sole way of gathering data is deemed as an appropriate and sufficient methodology (Marshall and Rossman, 1999).

So as to ensure this study answered the research questions, as well as to ensure consistency amongst the interviews, a measurement instrument, in the form of a semi structured interview protocol, was developed. Based on the review of the literature, four umbrella and twenty probing questions were developed to aid in the collection of data. For a review of the umbrella questions used in this study refer to Table 2 . The interviews, ranging in duration from 45 minutes to one and a half hours, were audio taped and transcribed for ease of comprehensive and systematic analysis. This included a process of "reduction" and "interpretation" (Marshall and Rossman, 1989).

\section{--- Take in Table 2}

Finally, so as to ensure discipline rather than relying on intuition (Stake, 1995), satisfaction of tests advocated by Yin (1994) namely, construct validity, internal validity, external validity, and reliability, discipline is afforded and, as such the validity and reliability of this study is increased. Specifically, through the application of multiple sources of evidence, the establishment of a chain of evidence and member checking 
coupled with strategies such as the use of replication logic, the use of semi-structured interview protocol and a case study database, the findings presented have been subject to disciplined inquiry.

\section{RESULTS AND DISCUSSION}

Upon the completion of the analysis of data collected, it was apparent that all participants promoted the concept of employee awareness of the organisation's brand to ensure employees' effectively carry out their roles and responsibilities. In other words, knowledge of the organisation's brand was seen as underpinning all tasks that related to delivering service quality in alignment with the brand. The importance of employees having brand knowledge was evidenced in the articulation of the organisation's "brand promise" in the employee handbook, individual department's operating plans, employee orientation and various employee-training sessions. The purpose of such articulation was to ensure employees had exposure to the promise that they, as service providers, were charged with the responsibility of delivering so as to ensure customer expectations were satisfied.

Several concepts were presented to the participants (refer to the four research questions) to uncover the managers' perspectives as to the extent to which the managers felt that they were necessary to ensure the employees' delivered a quality of service that was consistent with the organisation's brand promise. From this several themes were identified, namely, control, foundation, internal marketing, management role, direction, employee satisfaction, enhancers and element of control. As such, these themes are further discussed and a summary of results is presented in Table 3. 


\section{Control}

The identified theme of Control is defined here as the ability to regulate or govern employee behaviours to ensure consistency. With 2300 employees in the organisation that operates 24 hours a day, 7 days a week, it was not surprising that all ten participants advocated the need for systems and procedures to ensure service quality is controlled and aligned with the brand. For example, one interviewee stated, "You can imagine if they didn't follow those procedures, we won't be delivering the service, the brand and all of that sort of thing - it is very important that they do follow that."

The need for consistency underpins the Control theme for without it, participants perceived that there would be no service efficiency. According to the participants, Control is perceived to be engendered through the implementation of systems and procedures as they clearly outlined expectations of the organisation and in doing so, directed employees' behaviour. In fact, one comment was 'You need policies and procedures to clearly outline expectations - they give you a benchmark". Furthermore, participants believed that systems and procedures are required to ensure service delivery is consistent with the brand and the control inherent in the systems and procedures provided a mechanism to ensure such consistency. This being the case, the results here support the view that systems and procedures are necessary to ensure that the service quality delivered is aligned with the brand.

\section{Foundation}

However, seven of the ten managers interviewed perceived systems and procedures to represent the base or foundation upon which other factors, for example, knowledge of the brand, are built. The following statement is evidence of this -"I see it as a safety net - 
there are structures in place to protect us from going below what ever our quality standards are - people should be starting at that point and learning the fundamentals. "

The results suggest that systems and procedures were a necessary resource to guide or control employee behavior, but rather than be the exclusive factor, systems and procedures were seen as a complementary factor that provides a foundation upon which to build. As such, systems and procedures were not considered to be definitive, sometimes requiring alternative actions to be taken depending on the situation. For example, "When you have a large team you need to provide appropriate structure and guidance/instructions to team members to allow them to understand where their limits are and what is expected of them. At the same time I am forever saying, don't ever let a system stop you from delivering service".

This view is reflected in the literature where it is implied by de Chernatony and Dall'Olmo Riley (1999) that, while it is appropriate to implement systems and procedures to minimise the human error inherent in any service transaction, the standards prescribed need to be adaptable.

\section{Internal Marketing}

A view that was commonly held by nine of the ten participants was that Internal Marketing was very important to supplement the systems and procedures if the desired service quality was to be delivered. Internal Marketing, in relation to research question two, can be defined as a tool, other than systems and procedures, designed to help or enhance the employees' ability to behave accordingly. 
Training and internal communication were consistently mentioned as internal marketing tools that participants used to assist employees in delivering service quality in alignment with the brand promise. For example, one participant commented "Training and internal communication - definitely. The more people who are aware of what is happening in the progress of the business, the better they can manage situations ".

Communication, or internal marketing, was seen as an integral tool, as all participants agreed that employee awareness of the brand was imperative for successful execution of employees' roles and responsibilities. In particular, internal marketing, the method by which to align, motivate and integrate employee efforts towards the effective implementation of organisational initiatives as they relate to the customer, is considered to be an essential tool to ensure the consistent delivery of service quality (George, 1990; Rafiq and Ahmed, 2000, Asif and Sargeant, 2000). Organisations need to communicate what the brand stands for in order to encourage the employees to deliver the brand promise.

\section{Management Role}

Management Role, as it relates to research question two, is concerned with managers' responsibility in the transfer and application of employee related information. With the exception of three participants, all interviews reflected on the importance of managers playing an active role in ensuring employees deliver the appropriate service quality. This is evident in the following statement made by one of the participants when they said, "It is really up to the driver - like myself - and what I do with my two shift managers- it all falls back on your work ethic - a belief, a state of mind" 
Mentoring, support and encouragement as well as feedback are attributes that participants mentioned as being management traits that enable employees to deliver service quality in alignment with the brand promise. Furthermore, participants believe that they have a role to play in ensuring that employees deliver the appropriate service quality, as defined by the organisation's brand, as they are directly responsible for employee actions. This view is reflected in the literature where it is argued that managers must demonstrate how employees can carry out their roles and responsibilities while integrating new ideas about customer service and marketing on a daily basis (George, 1990). In doing so they will inspire the employees and help them understand how their roles relate to the brand (Harris and de Chernatony, 2001).

\section{Direction}

Direction can be thought of as providing employees with the necessary comprehension and guidance to successfully carry out their roles and responsibilities. Seven of the ten participants perceived having customer information to be very important for their employees to have the confidence to act appropriately. For example, one participant commented "Definitely - it changes their whole perception of what they are doing - their place, their fit in it, how important and the level of urgency". In an organization that promotes itself to be customer centric, the provision of customer information was perceived essential to supplement the systems and procedures as it provided employees with the necessary direction to interpret the articulated systems and procedures.

Our findings are along similar lines to the literature which suggests that for 'ideal performance' all employees must understand the expectations and requirements of customers (Kennedy, Lassk and Goolsby, 2002; Kohli and Jaworski, 1990; Narver and 
Slater, 1990), in order to act appropriately when engaging with a customer. The results of this study indicate that consumer knowledge or awareness provides employees with the necessary direction, should the systems and procedures need to be adapted, to satisfy the requirements of the customer. In doing so, consistency between employee behaviour and the brand is sustained.

\section{Employee Satisfaction}

Employee satisfaction as defined by this research, incorporates employees' contentment with their role. Knowing what to do i.e. direction, leads to the customer, and subsequent employee outcome of satisfaction. For example, "It is about caring - it is about filling them in with what is going on, why it is going on and making them part of delivering the brand - that makes them feel important - makes them feel part of this organisation". (Interviewee comment).

Sharing customer knowledge or making employees aware of their customers, according to six of the ten participants, supplements the systems and procedures. In doing so, employees feel involved in the brand delivery thus making them feel a sense of satisfaction. For example "it can be just a phone call where a guest has rung down to thank a team member for a good deed for the day....we remember to pass it on to that person because that is important. It pumps them up and encourages them to deliver that level of service to deliver the brand promise." (Interviewee comment)

Employees feel confident and, therefore, satisfied, that their actions are contributing to the organisation's objective of being customer aware or brand focussed when they receive customer related information. This is attributed to the fact that the employee's role is to create a satisfied customer (Jones, Busch and Dancin, 2003), and to do this 
successfully they need customer information. Without it, employees' perceptions of the consumers' expectations and the consumers' perceptions may in fact be completely different, resulting in an unsatisfactory service encounter for both the employee and the customer.

\section{Enhancers}

The theme of Enhancers can be defined as elements necessary for the systems and procedures to be relevant and meaningful in an applied setting. Four of the ten participants promoted customer knowledge/awareness as being a necessary enhancement to the systems and procedures to add the colour (i.e. examples) when interpreting black and white processes. In doing so, the processes become consistent with the customer centric philosophy of the business. For example, one manager expressed how being customer aware enhances the service encounter when they state "You can have customer service, do everything right and give everything a customer wants (following systems and procedures), yet their experience could have been better if a customer friendly system (customer aware) is in play." Furthermore, providing customer knowledge adds depth to the impersonal systems and procedures as is evident in the following statement "It would be too process oriented (without customer knowledge) - employees would have no ownership of it."

Thus, if an employee believes that information, for example customer knowledge, that is important to fulling their performance expectations is not widely distributed, employee's role ambiguity increases (Babin and Boles, 1996). This in turn negatively impacts employee's ability to be customer oriented (Jones et al, 2003). Therefore, the findings of this study suggest that the provision of customer knowledge or being customer aware enhances the systems and procedures, thereby decreasing role ambiguity. In doing so 
employees are able to be customer oriented and deliver service quality in alignment with the brand.

\section{Element of Control}

Of the ten interviews conducted, eight participants chose to modify the term empowerment as it was deemed to represent the potential for lack of control on the part of the organisation. The theme Element of Control can be defined as the establishment of parameters in which employees should work and the term empowerment, based on participants' experience, promoted limited control. For example "I worked in an organisation that promoted empowerment and it created chaos" (interviewee comment).

Participants felt more comfortable operating in a semi-controlled environment and perceived this to also be of benefit to the organisation. While establishing that the systems and procedures must be able to be modified to ensure the appropriate delivery of service quality in certain circumstances, participants reinforced that this did not mean the employees were empowered. Rather employees had the flexibility to act within a certain boundary thereby providing the managers with what they perceived to be a necessary element of control.

The findings of this study are in contrast to the view presented by Martin, Martin and Grbac, (1998) who believe that to effectively involve employees in customer-focussed strategies requires a culture that encourages employee empowerment. In doing so, employee empowerment is believed to increase efficiencies as employees coordinate their own activities across functions and all areas are customer focussed (Martin et al, 1998). In fact, the majority of managers in this study rejected the term empowerment, as it suggested limited or no control on the part of the organisation in guiding employee behaviour. 
One possible reason for this finding is the perceived difficulty in establishing the universal boundaries for empowerment. For example, "What is empowerment" or "my idea of being empowered to do something could overstep the mark or take away consistency in other confined areas" (interviewees comments). Consistent with the last comment there is also the inherent difficulty in managing a subjective process i.e. what is empowerment to one person maybe different to another and is largely defined by individual employees. When faced with an uncertain outcome, as would be the case when a manager empowers an employee, this research found that managers would prefer to have an element of control over the decisions made by their employees and, therefore, discarded the management tool of empowerment as discussed in the literature.

\section{CONCLUSION \& IMPLICATIONS}

The findings identify several themes that have been reflected in the extant literature in relation to the application of brand management initiatives. Furthermore, the emergence of global brands across all industries ensures that the insights of this study, afforded by the application of a qualitative methodology, have relevance both internationally and across industries. In particular, the results of this study reveal aspects that management need to consider ensuring the service quality delivered is aligned with the brand's values. This includes the necessity for systems and procedures to be implemented so as to provide the necessary control to ensure consistency of service delivery.

Further to this, the findings of this study reflected that while managers perceived control to be important, systems and procedures were not to be thought of as definitive, rather they provide a foundation upon which other elements are built, for example, knowledge 
of the brand. As such, internal marketing and the role of managers in helping to guide employee behaviour to deliver a service that is aligned with the brand, was also identified in this study and reflected in the literature, as being necessary to ensure employees are delivering the appropriate service.

The provision of customer related information was consider essential to the effective delivery of customer service as it not only enhanced the systems and procedures articulated but also provided employees with the necessary direction to effectively carry out their roles and responsibilities. Through the provision of direction, employee satisfaction was highlighted, as customer knowledge was perceived to reduce role ambiguity and conflict, as employees were aware as to how to engender a satisfactory service encounter through the comprehension of customer expectations.

Despite managers in this study identifying aspects, other than systems and procedures, that are necessary to deliver service quality in alignment with the brand, empowering employees was not considered to be necessary. In fact, managers reinforced the thinking that was initially presented, that being an element of control, was still needed to ensure a consistency in service delivery, especially in an organisation the employs over 2000 employees. These findings, therefore, have implications for both management and marketing theory.

\section{Management}

The results of this study revealed management's acknowledgement that employees have a significant role to play in an organisation that adopts brand management strategies. The themes identified in both the extant literature and this study, for example internal marketing, evidence the need for methods, in addition to systems and 
procedures, to be employed so as to ensure employees are successful in delivering a service that is consistent with the organisation's communicated brand values. Further to this, employees being aware of the organisation's brand and how to deliver the brand promise are believed to create direction and influence employee behaviour. In doing so employee role ambiguity and conflict is decreased.

As such, the results from this research suggest that for management to ensure employees' behaviour is aligned with the brand, they need to

- Consider the methods by which they can ensure the successful transfer of knowledge to employees that pertains to being customer focussed and what the organization's brand stands for;

- Develop linkages between the organisation' systems and procedures and other methods utilised to guide employee behaviour e.g. training, internal communication, so as to reflect the organisation's brand values;

- Clearly articulate and promote the tools that are to be used by employees to ensure the service quality delivered is aligned with the brand, namely systems and procedures, customer information, management guidance, internal marketing/communication;

- Continually engage with the employees in a manner consistent with the brand values of the organisation;

- Provide regular feedback to employees in relation to their customers through the provision of access to organisational market research reports as well as general customer comments received through informal channels. 
Whilst every effort has been made to minimise the limitations associated with this study several factors were apparent when conducting this project and, therefore, warrant being acknowledged. It is important to note, however, that the identification of these limitations does not invalidate the findings of this research, rather it points to further opportunities for research within this area of interest. Furthermore, as the results from this research can only be generalized to theory in light of the characteristics inherent in the adoption of case study methodology, further research in this area is suggested.

Firstly, it is important to note that while many of the findings of this study were consistent to that of the literature, only managers' perspectives were represented in the findings. As such, there was no measure as to the effectiveness of the managers' perspectives to enable a comparison of their actions and the subsequent outcomes. Such a measure was outside the scope of this exploratory study but does highlight an opportunity for further research to employ measurement tools such as customer satisfaction, employee satisfaction or financial indicators so as to compare management perspectives/actions with the outcomes generated in order to assess effectiveness.

In addition, the number of interviews for this study was selected based on the number of formalised subunits in the organisation so as to provide for the diversity of opinion within each of these units. Having said that, the ability for each interview to reflect the perceptions of the informal networks within each subunit, especially the ones with many employees, may not have been possible. Therefore, the themes identified may not, in fact, represent a comprehensive list. However, as the intention of this study was to enhance understanding of manager's perspectives in relation to the role employees play in the delivery of the brand in an applied setting, the selection of ten interviews representing the divisions of the organisation, was deemed satisfactory. According to 
Eisenhardt (1989), as the phenomenon of interest i.e. managers in each division, represents polar types within the case and are 'transparently observable', the number of interviews conducted was sufficient.

However, further research could enhance the understanding of the employees' perspective in delivering the brand within a service firm, if a more comprehensive multiple perspectives was explored, incorporating the insights of both front line employees as well as senior managers. This study focussed on the perspectives of front line managers only, however as organisations are complex phenomenon (Harris, 2002), incorporating the insights of both front line employees as well as senior managers would further enhance the level of comprehension and enable a comparison of perspectives between the levels of employment. The resulting factor would be the identification of implications that impact all key stakeholders as well as provide insight into the differences between managers and employees perspectives in relation to the role of the employee in delivering the brand. Furthermore, comparison amongst divisions could be made, identifying the differences in practices pertaining to delivering the brand promise as well as the evaluation of the subsequent outcomes from these practices.

Furthermore, so as to enhance the understanding of manager's perspectives of what is required, i.e. methods, for employees to effectively deliver service quality that is aligned with the brand; other organisations need to be considered. In particular, as this was based within a service context, further research in the manufacturing sector would provide insight into the extent to which employee alignment with the brand promise is necessary for the delivery of tangible product quality versus the intangible service quality. In doing so, this will increase our understanding of what themes are organizationally and industry specific and what themes are inherent in all organisations 
that try to make brand principles operational. Further research in this area has the potential to develop empirically tested themes that all brand focussed organizations need to consider when wanting to ensure there is alignment between the external customer's perceptions of the brand experience and the internal, service providers perceptions of the brand experience. 


\section{REFERENCES}

Aaker, D. and Joachimsthaler, E. (2000), Brand Leadership, Free Press, New York.

Amaratunga, D., Baldry, D., Sarshar, M. and Newton, R., (2002), "Quantitative and qualitative research in the built environment: application of "mixed" research approach", Work Study, Vol 51 No 1, pp. 17-31

Asif, S. and Sargeant, A., (2000), " Modelling internal communication in the financial services sector", European Journal of Marketing, Vol 34 No 3/4, pp. 299-318

Babin, B. J. and Boles, J.S., (1996), "The effects of perceived co-worker involvement and supervisor support on service provider role stress, performance and job satisfaction", Journal of Retailing, Vol 72 No 1, pp 57-75

Bachman, T., (2001), "Welcome back to the branch", Bank Marketing, Vol 33 No 1, pp. $40-47$

Balmer, J and Wilkinson, A., (1991), "Building societies: change strategy and corporate identity", Journal of General Management, Vol 17 No 2, pp. 20-33

de Chernatony, L. and Dall'Olmo Riley, F., (1997), "The chasm between managers' and consumers' views of brands: the experts' perspectives", Journal of Strategic Marketing, Vol 5, pp. 89-104 
de Chernatony, L. and Dall'Olmo Riley, F., (1998), "Modeling components of the brand", European Journal of Marketing, Vol 32 No 11/12, pp. 1074-1090

de Chernatony, L. and Dall'Olmo Riley, F., (1999), “Experts' views about defining service brands and the principles of service branding", Journal of Business Research, Vol 46, pp. 181-192

de Ruyter, K. and Scholl, N., (1998), "Positioning qualitative market research: reflections from theory and practice", Qualitative Market Research, Vol 1 No 1, pp. 7-14

Eisenhardt, K., (1989), "Building theories from case study research", The Academy of Management Review, Vol 41 No 4, pp. 532-550

George, W. R., (1990), "Internal marketing and Organizational Behaviour: A partnership in developing customer conscious employees at entry level", Journal of Business Research, Vol 20, pp. 63-70

Grace, D. and O'Cass, A., (2002), "Brand associations: looking through the eye of the beholder", Qualitative Market Research: An International Journal, Vol 5 No 2, pp. $96-111$

Gummeson, E., (1991), "Marketing - Orientation revisited: the crucial role of the part time marketer", European Journal of Marketing, Vol 25 No 2, pp. 60-75

Harris, F. and de Chernatony, L., (2001), "Corporate branding and corporate brand performance", European Journal of Marketing, Vol 35 No 3/4, pp. 441-456 
Harris, L. and Ogbonna, E., (2000), "The responses of front line employees to market oriented culture change", European Journal of Marketing, Vol 34 No 3/4, pp. 318340

Harris, L.C., (2002), "Sabotaging market-oriented culture change: an exploration of resistance justifications and approaches", Journal of Marketing Theory and Practice, Vol 10 No 3, pp. 58-74

Hill, J. and McGowan, P., (1999), "A qualitative approach to developing small firm marketing planning competencies", Qualitative Market Research, Vol 2 No 3, pp. 167175

Joia, L.A., (2002), " Analysing a web-based e-commerce learning community: a case study in Brazil", Internet Research: Electronic Networking Applications and Policy, Vol 12 No 4, pp. $305-317$

Jones, E., Busch, P. and Dacin. P., (2003), "Firm market orientation and salesperson customer orientation: interpersonal and intrapersonal influences on customer service and retention in business-to-business buyer-seller relationships", Journal of Business Research, Vol 56, pp. 32-340

Keller, K. (1998), Strategic Brand Management, Prentice Hall, Upper Saddle River, NJ 
Keller, K.L., (1993), "Conceptualising, measuring and managing customer based brand equity", Journal of Marketing, Vol 57 (January), pp. 1-22

Kennedy, K.N., Lassk, F. G. and Goolsby, J.R., (2002), "Customer Mind-set of Employees Throughout the Organisation", Journal of the Academy of Marketing Science, Vol 30 No 2, pp. 159-171

Kerin, R. and Sethuraman, R., (1998), "Exploring the brand value shareholder value nexus for consumer goods companies", Journal of Academy Marketing Science, Vol 26 No 4, pp. 260-273

Khermouch, G., Holmes, S. and Ihlwan, M. (2001), "The best global brands together with leading brand consultant Interbrand, we've ranked the leaders around the world", Business Week, No 3744, pp. 50-55

Kohli, A. and Jaworski, B., (1990), "Market orientation: the construct, research propositions and managerial implications", Journal of Marketing, Vol 54 No 2, pp. 35-58

Kotler, P., Armstrong, G., Meggs, D., Bradbury, E. and Grech, J. (1999), Marketing an Introduction, Prentice Hall, Australia.

Lassar, W., Mittal, B. and Sharma, A., (1995),"Measuring customer based brand equity", Journal of Consumer Marketing, Vol 12 No 4, pp. 11-19

Levitt, T., (1972), "Marketing intangible products and product intangibles", Harvard Business Review, Vol 50 (September-October), pp. 94-102 
Marshall, C. and Rossman, G. B. (1999), Designing Qualitative Research- $3^{\text {rd }}$ edition, Sage Publications, California.

Martin, J.H., Martin, B.A. and Grbac, B., (1998), "Employee Involvement and Market Orientation in a transition economy: Importance, problems and a solution", Journal of Managerial Issues, Vol 10 No 4, pp. 485-502

McDonald, M., de Chernatony, L. and Dall'Olmo Riley, F., (2001), "Corporate marketing and service brands - moving beyond the fast moving consumer goods model", European Journal of Marketing, Vol 35 No 3/4, pp. 335-352

Narver, J. and Slater, S., (1990), "The effect of a market orientation on business profitability", Journal of Marketing, Vol 54 No 5, pp. 20-35

Noble, C.H., Rajiv, K.S. and Kumar, A., (2002), "Market Orientation and alternative strategic orientations: A longitudinal assessment of performance implications", Journal of Marketing, Vol 66 No 4, pp. 25-39

Pulendran, S., Speed, R. and Widing II, R., (2000), "The antecedents and consequences of market orientation in Australia", Australian Journal of Management, Vol 25 No 2, pp. 119-144

Rafiq, M. and Ahmed, P., (2000), "Advances in the internal marketing concept: definition, synthesis and extension", Journal of Services Marketing, Vol 14 No 6, pp. $449-462$ 
Samli, A. and Frohlich, C., (1992), "Service: the competitive edge in banking", Journal of Services Marketing, Vol 6 No 1, pp. 15-22

Schneider, B and Bowen, D., (1985), "Employee and customer perceptions of service in banks: replication and extension", Journal of Applied Psychology. Vol 70, pp. $423-433$

Schultz, D.E., (1999), "Perhaps the 4Ps should be the 4Rs", Marketing News, Vol 33 No 11, pp. 7

Simoes, C. and Dibb, S., (2001), "Rethinking the brand concept: New brand orientation", Corporate Communications, Vol 6 No 4, pp. 217

Spreng, R. and MacKoy, R., (1996), "An empirical examination of a model of perceived service quality and satisfaction", Journal of Retailing, Vol 72 No 2, pp. 201214

Spreng, R., Harrell, G. and MacKoy, R., (1995), "Service Recovery: Impact on satisfaction and retention", Journal of Services Marketing, Vol 9 No 1, pp. 15-23

Stake, R.E. (1995), The art of case study research, Sage Publications, California.

Sureshchandar, G., Rajendran, C. and Anantharaman, O., (2002), "The relationship between service quality and customer satisfaction - A factor specific approach", Journal of Services Marketing, Vol 16 No 4, pp. 363-379 
Thakor, M and Katsanis, L., (1997), "A model of brand and country effects on quality dimensions: Issues and implications", Journal of International Consumer Marketing, Vol 9 No 3, pp. 15-30

Varey, R., (1995), "Internal Marketing: a review and some interdisciplinary research", International Journal of Service Industry management, Vol 6 No 1, pp. 40

Yin, R.K. (1994), Case Study Research - Design and methods ( $\left.2^{\text {nd }} e d\right)$, Sage Publications, California.

Yin, R.K. (2003), Case Study Research - Design and methods ( $3^{\text {rd }}$ ed), Sage Publications, California.

Zikmund, W.G. (1997), Exploring Market Research, $6^{\text {th }}$ edition, The Dryden Press, Orlando, FL. 
Table 1 Profile of participants

\begin{tabular}{|c|c|c|c|c|}
\hline Interview & Division & Sex & Age & $\begin{array}{c}\text { Duration of } \\
\text { employment } \\
\text { (Years) }\end{array}$ \\
\hline 1 & Human Resources & Male & 38 & 2 \\
\hline 2 & Finance & Male & 28 & 6 \\
\hline 3 & Gaming & Female & 27 & 10 \\
\hline 4 & Food \& Beverage & Male & 32 & 4 \\
\hline 5 & Other & Male & 50 & 15 \\
\hline 6 & Hotel & Female & 55 & 18 \\
\hline 7 & Other & Female & 28 & 3 \\
\hline 8 & Hotel & Female & 38 & 10 \\
\hline 9 & Gaming & Male & 33 & 7 \\
\hline 10 & Food \& Beverage & Male & 40 & 1 \\
\hline
\end{tabular}




\section{Table 2 Umbrella Questions}

Research Question 1: To what extent do managers believe that the delivery of service quality in alignment with the brand is dependant upon the implementation of systems and procedures?

Umbrella Question - Can you explain to me what systems and procedures (e.g. how to make a coffee/bed/reservation, how to deal a hand, how to change a light bulb) you have in place in order for employees to carry out their roles and responsibilities in line with the brand?

Research Question 2: Apart from the implementation of systems and procedures, what other factors do managers believe assist employees in delivering service quality in alignment with the brand promise?

Umbrella Question - Do you employ any other initiatives other than systems and procedures to help improve service quality in the delivery of the brand promise e.g. training, general knowledge transfer, cross training, internal communication?

Research Question 3: To what extent do managers believe that consumer knowledge/awareness is necessary to supplement the systems and procedures implemented to deliver service quality in line with the brand promise?

Umbrella Question - Do you actively share customer knowledge/insights with your employees? Why?

Research Question 4: To what extent do managers believe that employee empowerment is necessary to supplement the systems and procedures implemented to deliver service quality in line with the brand promise?

Umbrella Question - Does your organisation encourage employees to take the extra step and use their initiative (empower)? 
Table 3 Summary of results

\begin{tabular}{|c|c|c|c|c|c|c|c|c|c|c|}
\hline Interviewee & 1 & 2 & 3 & 4 & 5 & 6 & 7 & 8 & 9 & 10 \\
\hline \multicolumn{11}{|c|}{$\begin{array}{l}\text { Research Question 1: To what extent do managers believe that the delivery of service quality in } \\
\text { alignment with the brand is dependant upon the implementation of systems and procedures? }\end{array}$} \\
\hline Control & $X$ & $X$ & $x$ & $x$ & $x$ & $X$ & $X$ & $x$ & $\mathrm{X}$ & $\mathrm{X}$ \\
\hline Foundation & $X$ & $X$ & $x$ & $x$ & & & $X$ & $x$ & $x$ & \\
\hline \multicolumn{11}{|c|}{$\begin{array}{l}\text { Research Question 2: Apart from the implementation of systems and procedures, what other } \\
\text { factors do managers believe assist employees in delivering service quality in alignment with the } \\
\text { brand promise? }\end{array}$} \\
\hline $\begin{array}{l}\text { Internal } \\
\text { Marketing }\end{array}$ & $X$ & $X$ & & $X$ & $X$ & $X$ & $X$ & $x$ & $x$ & $x$ \\
\hline $\begin{array}{l}\text { Management } \\
\text { Role }\end{array}$ & $X$ & $X$ & $x$ & & $X$ & & & $X$ & $x$ & $X$ \\
\hline \multicolumn{11}{|c|}{$\begin{array}{l}\text { Research Question 3: To what extent do managers believe that consumer knowledge/awareness } \\
\text { is necessary to supplement the systems and procedures implemented to deliver service quality in } \\
\text { line with the brand promise? }\end{array}$} \\
\hline Direction & $X$ & $X$ & $x$ & & & & $X$ & $\mathrm{X}$ & $x$ & $x$ \\
\hline $\begin{array}{l}\text { Employee } \\
\text { Satisfaction }\end{array}$ & & & & $X$ & $\mathrm{X}$ & $X$ & & $x$ & $\mathrm{X}$ & $X$ \\
\hline Enhancers & $x$ & $\mathrm{X}$ & & & $x$ & & $X$ & & & \\
\hline \multicolumn{11}{|c|}{$\begin{array}{l}\text { Research Question 4: To what extent do managers believe that employee empowerment is } \\
\text { necessary to supplement the systems and procedures implemented to deliver service quality in line } \\
\text { with the brand promise? }\end{array}$} \\
\hline $\begin{array}{l}\text { Element of } \\
\text { control }\end{array}$ & $X$ & $X$ & $x$ & $x$ & $\mathrm{X}$ & & $X$ & $\mathrm{X}$ & & $x$ \\
\hline
\end{tabular}


FIGURE 1

DOUBLE VORTEX MODEL

de Chernatony and Dall'Olmo Riley, 1998, p.1085

Time

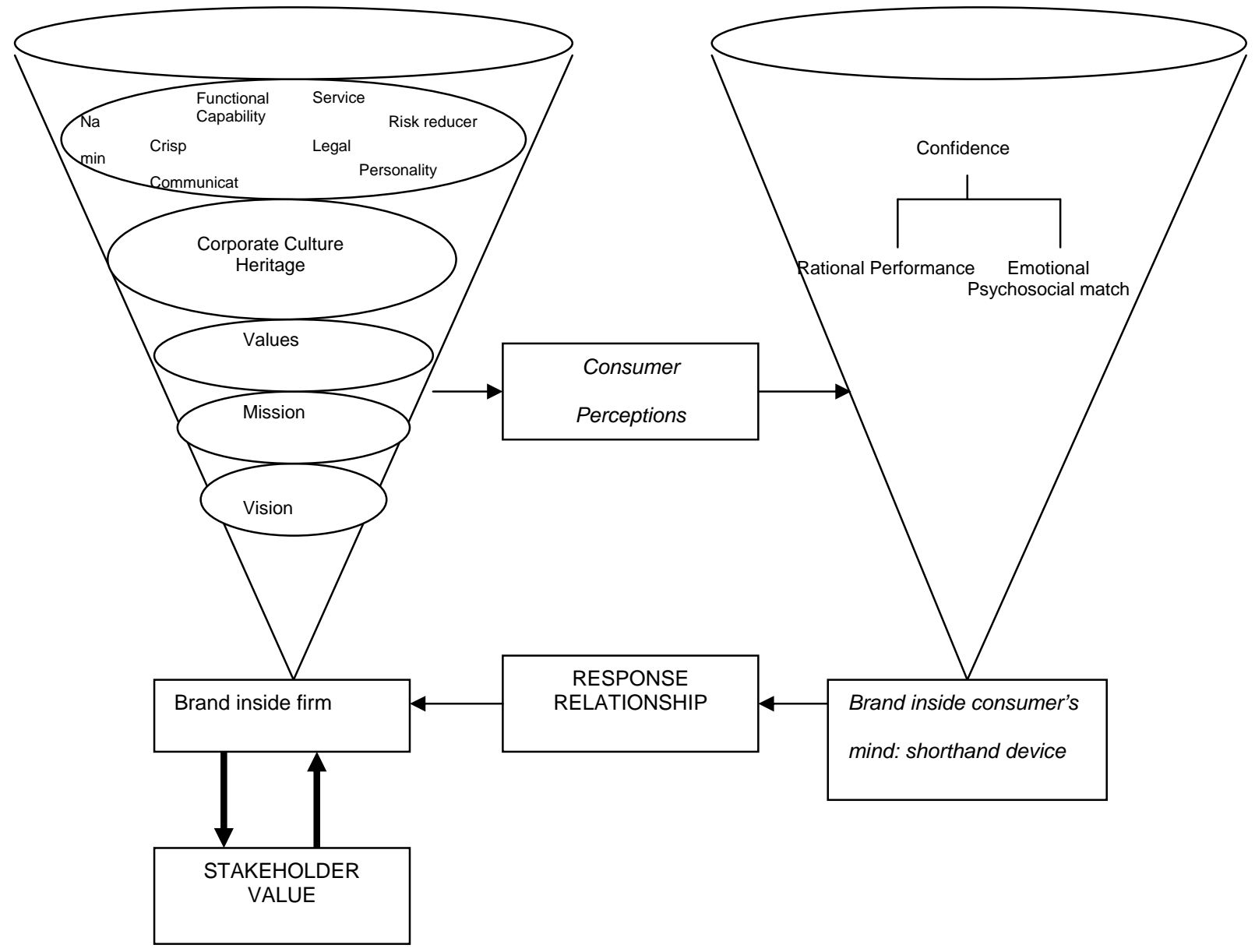

